\title{
BB LOCA analysis for the reference design of the EU DEMO HCPB blanket concept Xue Zhou Jin
}

Accident sequences and assumptions

\begin{tabular}{|c|c|c|c|c|c|c|c|c|}
\hline \multicolumn{5}{|c|}{ LOCA case } & \multirow{2}{*}{\multicolumn{2}{|c|}{$\begin{array}{l}\text { I (in-BB) } \\
C P \text { in BZ }\end{array}$}} & \multicolumn{2}{|c|}{ II (in-vessel) } \\
\hline \multirow{2}{*}{\multicolumn{5}{|c|}{$\begin{array}{l}\text { Failure condition } \\
\text { Scenario }\end{array}$}} & & & \\
\hline & & & & & la & $\mathrm{Ib}$ & Ila & $\mathrm{Ilb}$ \\
\hline \multirow[t]{5}{*}{ Assumptions } & \multicolumn{4}{|c|}{ Failed cooling channel } & 1 & $32(1 \mathrm{CP})$ & 1 & 10 \\
\hline & \multicolumn{4}{|c|}{$A_{b}\left(m^{2}\right)$} & $3.0 e-5$ & $9.6 \mathrm{e}-4$ & $3.125 e-4$ & $3.125 \mathrm{e}-3$ \\
\hline & \multicolumn{4}{|l|}{ He ingress into } & \multicolumn{2}{|c|}{ PG } & \multicolumn{2}{|c|}{ VV } \\
\hline & \multirow{2}{*}{\multicolumn{4}{|c|}{$\begin{array}{l}\text { Bleed line / RD } \\
\text { A PG / A VV / A RD }\left(\mathrm{m}^{2}\right)\end{array}$}} & \multirow{2}{*}{\multicolumn{2}{|c|}{$\frac{p_{P G}>0.5 \mathrm{MPa}}{13254 \mathrm{e}-2}$}} & \multicolumn{2}{|c|}{$\mathrm{p}_{\mathrm{VV}}>90 \mathrm{kPa} / 150 \mathrm{kPa}$} \\
\hline & & & & & & & \multicolumn{2}{|c|}{$0.05 / 1.0$} \\
\hline \multirow{11}{*}{$\begin{array}{l}\text { Time } \\
\text { evolution (s) }\end{array}$} & \multirow{2}{*}{\multicolumn{4}{|c|}{\begin{tabular}{|l|} 
Steady state $/$ LOCA \\
$\mathrm{HTC}=0.0$ \\
\end{tabular}}} & \multicolumn{4}{|c|}{1000} \\
\hline & & & & & \multirow{2}{*}{\multicolumn{4}{|c|}{$\begin{array}{c}>1000 \\
1003\end{array}$}} \\
\hline & \multicolumn{4}{|c|}{ compressor shutdown } & & & & \\
\hline & \multirow{8}{*}{$\begin{array}{l}\text { Plasma shutdown } \\
\text { condition }\end{array}$} & \multirow[t]{6}{*}{ FPSS } & \multirow{6}{*}{$\begin{array}{l}\text { Plasma } \\
\text { disruption } \\
(0.5 \text { GJ) }\end{array}$} & \multirow[t]{2}{*}{ (1) no } & \multicolumn{2}{|c|}{1004} & \multicolumn{2}{|c|}{1004} \\
\hline & & & & & \multirow{2}{*}{\multicolumn{2}{|c|}{\begin{tabular}{c|l} 
(casela1) & (caselb1) \\
$1004 \sim 1004.1$
\end{tabular}}} & \multicolumn{2}{|c|}{\begin{tabular}{l|l} 
(casella1) & (casellb1) \\
\end{tabular}} \\
\hline & & & & \multirow[t]{2}{*}{ (2) $100 \mathrm{~ms}$} & & & \multicolumn{2}{|c|}{$1004 \sim 1004.1$} \\
\hline & & & & & (casela2 & (caselb2) & (casella2) & (casellb2) \\
\hline & & & & \multirow[t]{2}{*}{ (2') $10 \mathrm{~ms}$} & \multirow{2}{*}{\multicolumn{2}{|c|}{ - }} & \multicolumn{2}{|c|}{$1004 \sim 1004.01$} \\
\hline & & & & & & & (casella2') & (casellb2') \\
\hline & & (3) So & ft plasma s & nutdown & 1004 & -1064 & & - \\
\hline & & (60s) & & & (casela3 & (caselb3) & & \\
\hline
\end{tabular}

OB4 model and LOCA conditions using MELCOR186 for fusion
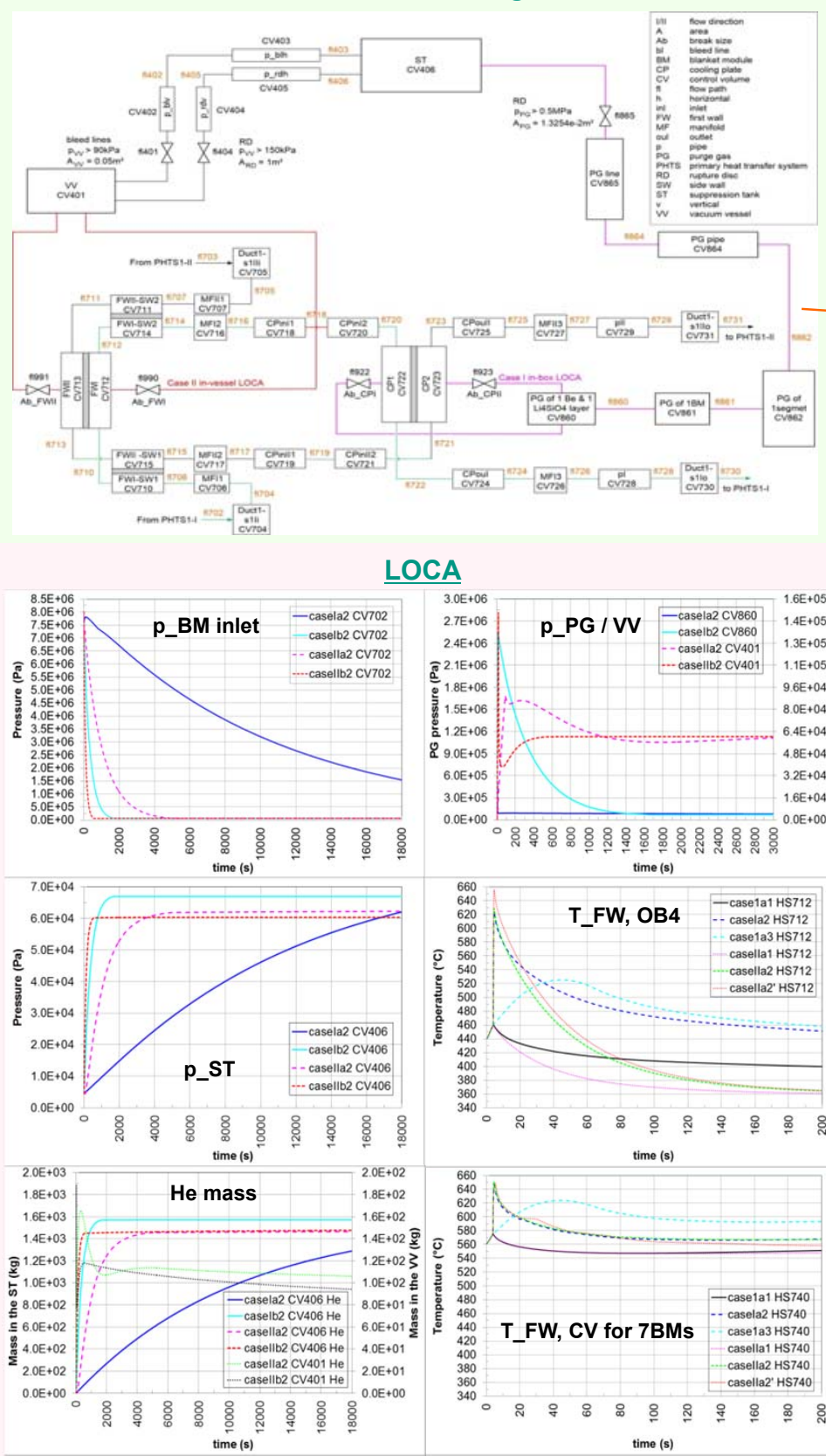

LOCA
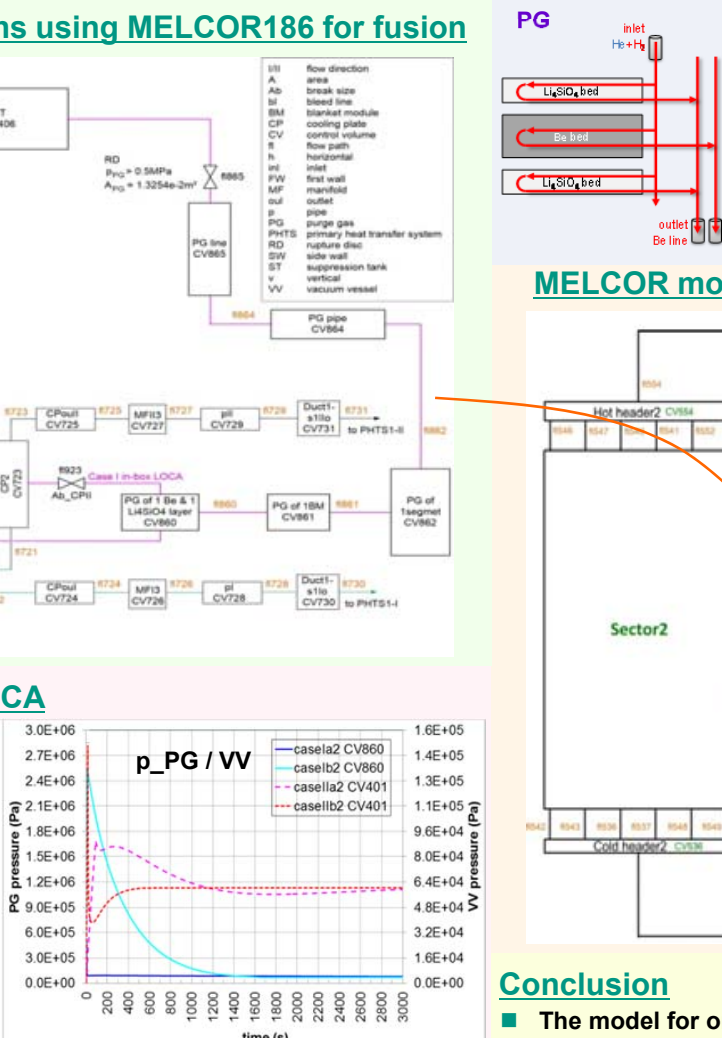

Reference design for DEMO2015 with 18TFs
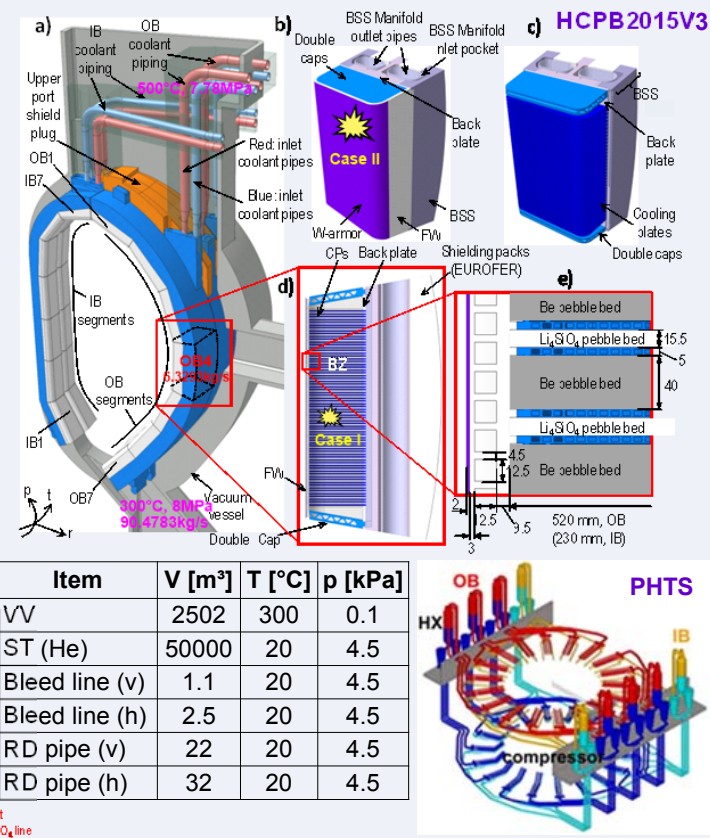

MELCOR modelling for one OB loop with the integrated OB4

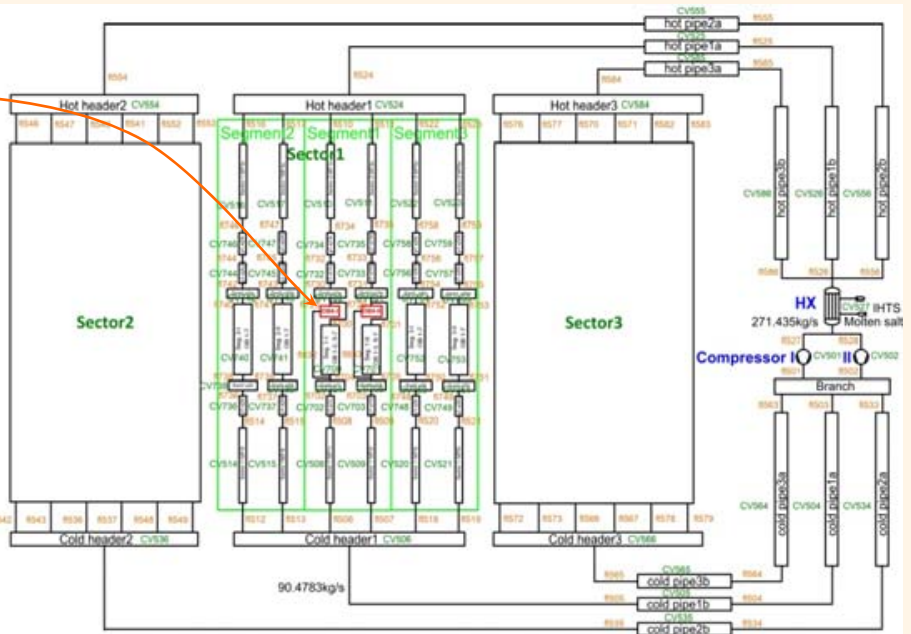

Conclusion

- The model for one OB loop including 3 OB sectors results comparable He flow behaviour to the blanket design in normal operation.

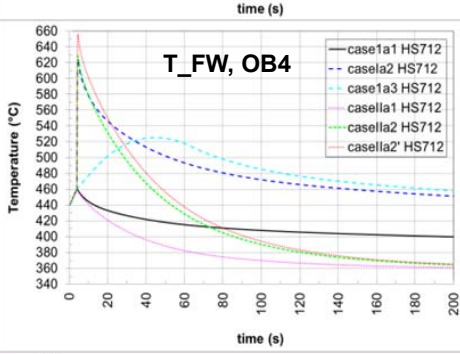

- He inventory of one loop is $1.5848 \mathrm{e} 3 \mathrm{~kg} \Rightarrow 9.5090 \mathrm{e} 3 \mathrm{~kg}$ for 6 OB loops $\Rightarrow$ challenge for the dimensioning of the pressure relief systems in case of invessel, in-BB or ex-vessel LOCA.

- The break size has impact on the He ingress with respect to the time evolution of the mass flow rate, pressure, temperature and mass:

- Small FW break size decelerates the He loss speed, pressure drop and temperature decrease in the affected module, and He accumulation in the VV.

- The plasma shutdown condition has impact on the FW temperature:

- The high heat flux load caused by short disruption time leads to high temperature peak exceeding the design limit.

- The in-vessel LOCA affects the VV, while the in-BB LOCA can affect the tritium extraction removal (TER) system potentially.

- In casellb, the final pressure at equilibrium $\left(p_{\text {fin }}\right)$ is $\sim 60 \mathrm{kPa}$ with $V_{\text {st }}$ of $50000 \mathrm{~m}^{3}$ To reach $p_{\text {fin }}$ at $200 \mathrm{kPa}\left(p_{\mathrm{Vv} \_ \text {limit }}\right)$, $V_{s+1}$ is $12476 \mathrm{~m}^{3} \Rightarrow 74856 \mathrm{~m}^{3}$ for 6 OB loops.

- To reduce $V_{\text {st: }}$ add subcooled water in the ST \& heat exchange to the environment.

- Investigation of 3D thermal analysis for T_FW, and loop update for new design.

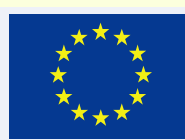

his work has been carried out within the framework of the EUROfusion Consortium and has received funding from the

Euratom research and training programme 2014-2018 under grant agreement № 633053. The views and opinions expressed here do not necessarily reflect those of the European Commission. 